\title{
Vancomycin-resistant enterococcal infections: epidemiology, clinical manifestations, and optimal management
}

This article was published in the following Dove Press journal:

Infection and Drug Resistance

24 July 2015

Number of times this article has been viewed

\author{
Tristan O'Driscoll' \\ Christopher W Crank ${ }^{2}$ \\ 'Department of Pharmacy Practice, \\ Chicago College of Pharmacy, \\ Downers Grove, IL, USA; ${ }^{2}$ Pharmacy \\ Services, Rush-Copley Medical \\ Center, Aurora, IL, USA
}

\begin{abstract}
Since its discovery in England and France in 1986, vancomycin-resistant Enterococcus has increasingly become a major nosocomial pathogen worldwide. Enterococci are prolific colonizers, with tremendous genome plasticity and a propensity for persistence in hospital environments, allowing for increased transmission and the dissemination of resistance elements. Infections typically present in immunosuppressed patients who have received multiple courses of antibiotics in the past. Virulence is variable, and typical clinical manifestations include bacteremia, endocarditis, intra-abdominal and pelvic infections, urinary tract infections, skin and skin structure infections, and, rarely, central nervous system infections. As enterococci are common colonizers, careful consideration is needed before initiating targeted therapy, and source control is first priority. Current treatment options including linezolid, daptomycin, quinupristin/ dalfopristin, and tigecycline have shown favorable activity against various vancomycin-resistant Enterococcus infections, but there is a lack of randomized controlled trials assessing their efficacy. Clearer distinctions in preferred therapies can be made based on adverse effects, drug interactions, and pharmacokinetic profiles. Although combination therapies and newer agents such as tedizolid, telavancin, dalbavancin, and oritavancin hold promise for the future treatment of vancomycin-resistant Enterococcus infections, further studies are needed to assess their possible clinical impact, especially in the treatment of serious infections.
\end{abstract}

Keywords: Gram-positive, Enterococcus faecalis, Enterococcus faecium, VRE, antibiotic resistance, multidrug resistance

\section{Introduction}

Vancomycin-resistant Enterococcus (VRE), belonging to the species Enterococcus faecium, was first encountered in clinical isolates in England and France in 1986, followed the next year by isolation of VRE faecalis in the United States. ${ }^{1-3}$ In Europe, the rise of VRE was principally in the community setting, due to transmission from animal food products to humans, thought to arise from the use of a glycopeptide antibiotic avoparcin as a growth promoter in livestock, ${ }^{4}$ whereas in the US the predominance of VRE was in the hospital setting, believed to be due to the increasing use of the glycopeptide antibiotic vancomycin. ${ }^{5}$ Subsequently, the US experienced a rapid spread of VRE in hospitals in the 1990s, Europe followed suit in the 2000s, and eventually a worldwide spread ensued. ${ }^{6-8}$ In 2002 , the threat of VRE colonization and infections increased when the first patient case of VRE transmitting vanA resistance genes to methicillin-resistant Staphylococcus aureus (MRSA) to form a vancomycin-resistant Staphylococcus aureus (VRSA) isolate was reported. ${ }^{9}$
Correspondence: Christopher W Crank Rush-Copley Medical Center, 2000 Ogden Avenue, Aurora, IL 60504, USA

Tel + I 6309784853

Email ccrank@rushcopley.com 
Currently, 54 different species and two subspecies of enterococci have been described, with E. faecalis and E. faecium being the most clinically relevant species, isolated in the US at a ratio of 1.6:1, respectively. ${ }^{8,10}$ E. faecalis is more pathogenic than E. faecium, but the latter exhibits more resistance, composing the majority of VRE infections. ${ }^{11,12}$ The emergence of VRE as an important nosocomial pathogen is due to its propensity for colonization of the gastrointestinal (GI) tract, persistence in hospital environments, genome plasticity, mobile genetic elements, and increased mortality. ${ }^{13}$ Due to the multiple resistance mechanisms found in VRE, treatment options are limited, but several new agents have come to market recently and recent data on combination therapies have looked promising, broadening the treatment options that are currently available. This review highlights the epidemiology, clinical manifestations, and optimal management of VRE infections.

\section{Resistance}

Enterococci are incredibly efficient at attaining antimicrobial resistance, displaying a variety of mechanisms for acquired and intrinsic resistance. They have remarkable genome plasticity and utilize plasmids, transposons, and insertion sequences to efficiently attain and transfer mobile resistance elements, facilitating dissemination of resistance genes. ${ }^{14}$

\section{$\beta$-lactam resistance}

Enterococci exert a low-level intrinsic resistance to $\beta$-lactams due to penicillin-binding proteins (PBPs) with a low-affinity for these agents. ${ }^{15}$ Compared to streptococci, E. faecalis is 10-100-fold less sensitive to penicillin, and compared to E. faecalis, E. faecium is 4-16-fold less susceptible. ${ }^{16}$ Therefore, most enterococci are tolerant to the bactericidal activity of $\beta$-lactams, making them bacteriostatic. However, if bactericidal activity is needed to treat severe infections such as endocarditis or meningitis, a synergistic bactericidal combination of a $\beta$-lactam with an aminoglycoside can be used. ${ }^{17,18}$

High-level $\beta$-lactam resistance in enterococci is principally due to two mechanisms: the production of low-affinity PBP5, or the production of $\beta$-lactamases. ${ }^{18}$ Overproduction of PBP5 with low-affinity binding to $\beta$-lactams is characteristic of E. faecium but uncommon among E. faecalis. ${ }^{19}$ In fact, most VRE faecium strains in the US express high-level resistance (HLR) to ampicillin, while most VRE faecalis strains remain susceptible to ampicillin. ${ }^{14,20}$ The production of $\beta$-lactamases is infrequent in enterococci, but can lead to HLR by hydrolyzing $\beta$-lactams before they reach their target in the cell wall. It is almost universally due to E. faecalis strains and is constitutive, low level, and inoculum-dependent. ${ }^{21}$

\section{Aminoglycoside resistance}

Enterococci are intrinsically resistant to low levels of aminoglycosides due to decreased cellular permeability of these agents, but this can be overcome with the addition of a cellwall-active agent such as a $\beta$-lactam, which increases the entry of the aminoglycoside into the cell. ${ }^{17}$

First reported in the US in 1979, HLR to gentamicin was found in both E. faecalis and E. faecium, and was followed shortly by the isolation of HLR to both gentamicin and streptomycin in $1983 .{ }^{22,23}$ HLR to aminoglycosides is acquired through two mechanisms of resistance: modification of ribosomal attachments sites, and the production of aminoglycoside-modifying enzymes. ${ }^{17}$ Gentamicin or streptomycin are the recommended synergy agents for use with $\beta$-lactams to obtain bactericidal activity. The presence of HLR to aminoglycosides destroys the bactericidal activity obtained with $\beta$-lactam and aminoglycoside synergy in clinical practice. ${ }^{24}$

\section{Glycopeptide resistance}

Bacterial cell walls are made of peptidoglycan that is formed when cell wall pentapeptide precursors ending in D-Ala-DAla translocate from the cytoplasm to the cell surface and are incorporated into nascent peptidoglycan by transglycosylation, forming cross-links by transpeptidation to strengthen the cell wall. ${ }^{25}$ Glycopeptides, such as vancomycin and teicoplanin, are cell-wall-active agents, exerting their antibacterial effect by binding with high affinity to the D-Ala-DAla termini of pentapeptide precursors in order to inhibit the synthesis of peptidoglycan. Glycopeptide resistance arises when low-affinity pentapeptide precursors D-Ala-D-Lac or D-Ala-D-Ser are formed and high-affinity precursors D-AlaD-Ala are eliminated. ${ }^{26}$

Currently, eight phenotypic variants of acquired glycopeptide resistance in enterococci have been described (VanA, VanB, VanD, VanE, VanG, VanL, VanM, and VanN), with one type of intrinsic resistance (VanC) being unique to E. gallinarum and E. casseliflavus (Table 1). ${ }^{27-31}$ A change in the precursor to D-Ala-D-Lac (VanA, VanB, VanD, VanM) causes a 1,000-fold decrease in affinity for vancomycin, and a change to D-Ala-D-Ser (VanC, VanE, VanG, VanL, VanN) causes a 7-fold decrease in affinity for vancomycin. ${ }^{32,33}$ VanA is responsible for most of the human cases of VRE around the world, and is mostly carried by E. faecium. 


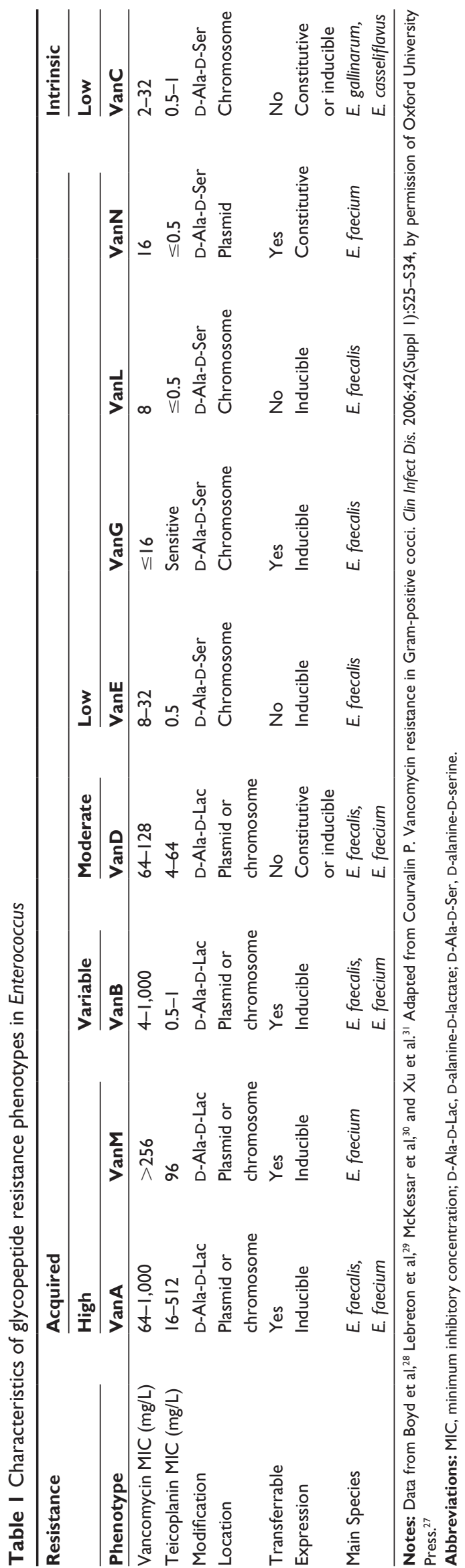

\section{Epidemiology Colonization, transmission, and risk factors}

The majority of VRE colonization occurs in the GI tract, but can also be found to a lesser extent on the skin, in the genitourinary (GU) tract, and in the oral cavity. ${ }^{34,35}$ E. faecalis is the major colonizer in these sites. Once GI colonization with VRE occurs, it can persist for months to years and efforts at decolonization are typically transitory, with recurrence of VRE days or weeks later. ${ }^{36,37}$ Health care workers' hands are the most consistent source of transmission. ${ }^{38}$ VRE can persist for up to 60 minutes on hands and as long as 4 months on surfaces. ${ }^{39,40}$ The common pathway for nosocomial VRE starts with acquisition via personto-person contact or exposure to contaminated objects. Gut microbiota are then suppressed through antimicrobial selective pressure, allowing for overgrowth of VRE, as it is intrinsically resistant to several antibiotics. When the patient becomes immunosuppressed, VRE can flourish, causing a clinical illness. ${ }^{34}$

Risk factors for colonization include host characteristics and exposure to antimicrobials. An increased risk of VRE colonization occurs with immunosupression, hematological malignancies, organ transplantation, increased intensive care unit (ICU) or hospital stay, residence in a long-term care facility, infection of an additional body site, proximity to another colonized or infected patient, hospitalization in a unit with a high prevalence of VRE, serious comorbid conditions such as diabetes, renal failure, and high Acute Physiology and Chronic Health Evaluation (APACHE) II scores. ${ }^{41-44}$ Prior exposure to antimicrobials is the largest predictor of VRE colonization, including oral and intravenous (IV) administration of vancomycin, ${ }^{45}$ aminoglycosides, ${ }^{46}$ cephalosporins, ${ }^{47,48}$ antianaerobic agents such as clindamycin and metronidazole, and carbapenems. ${ }^{46}$

\section{Distribution of VRE}

Among enterococci, E. faecalis is the most common cause of infections, but $E$. faecium is intrinsically more resistant to antibiotics with more than half of nosocomial isolates in the US expressing resistance to ampicillin and vancomycin and HLR to aminoglycosides. ${ }^{49}$

Around the world, the rates of VRE are at their highest in North America (Table 2). According to the National Healthcare Safety Network (NHSN), from 2009 to 2010, 35.5\% of enterococcal hospital-associated infections were resistant to vancomycin, ranking as the second most common cause of nosocomial infections in the US. ${ }^{11}$ In contrast, Canada has a 
Table 2 Surveillance of vancomycin-resistant enterococci around the world

\begin{tabular}{|c|c|c|c|c|c|c|}
\hline \multirow[t]{3}{*}{ Species } & \multicolumn{6}{|c|}{ Percent of Enterococcus isolates resistant to vancomycin by region (no of isolates) } \\
\hline & Europe $^{8}$ & US"I & Worldwide 115 & Canada $^{50}$ & Asia-Pacific 118 & Latin America ${ }^{1 / 8}$ \\
\hline & 2013 & 2009-2010 & $2007-2012$ & 2007-20II & 2007-2008 & 2007-2008 \\
\hline E. faecium & $8.8(729)$ & $79.4(2,572)$ & - & $22.4(60)$ & I4.I (270) & $48.1(54)$ \\
\hline E. faecalis & $\mathrm{I} .0(126)$ & $8.5(444)$ & $10.3(27)$ & $0.1(I)$ & 0.01 (440) & 3.1 (195) \\
\hline All enterococci & $4.0(855)$ & $35.5(3,016)$ & - & $6.0(6 \mathrm{I})$ & $11.9(7 \mid 0)$ & 12.9 (249) \\
\hline
\end{tabular}

Note: Adapted by permission of Oxford University Press from Cattoir V, Leclercq R. Twenty-five years of shared life with vancomycin-resistant enterococci: is it time to divorce? J Antimicrob Chemother. 2013;68(4):73I-742. ${ }^{14}$

Abbreviations: VRE, vancomycin-resistant Enterococcus; US, United States.

much lower prevalence of VRE; according to CANWARD, $6 \%$ of enterococci in Canada were resistant to vancomycin from 2007 to $2011 .^{50}$

In Europe, VRE is much less prevalent, but on the rise. For 2013, the European Antimicrobial Resistance Surveillance System (EARSS) reported only $4 \%$ prevalence of VRE. ${ }^{8}$ However, this prevalence is variable depending on the country, with VRE ranging from less than 1\% in France, Spain, and Sweden, to greater than $20 \%$ in Greece, Ireland, Portugal, and the United Kingdom.

\section{Clinical manifestations}

\section{Bacteremia}

Bacteremia without endocarditis is a common presentation of enterococcal disease, especially in debilitated patients who are seriously ill and receiving antibiotics. ${ }^{51}$ In the US, $18 \%$ of all central line associated bloodstream infections (CLABSIs) are due to enterococci, ranking second overall. ${ }^{11}$ Common sources for community-acquired bacteremia are the GI and GU tracts. ${ }^{52}$ Nosocomial enterococal bacteremias are commonly acquired from intravascular or urinary catheters, but have also been associated with intra-abdominal, burn wounds, pelvic, biliary, and bone sources. VRE bacteremia is associated with a 2.5 -fold increase in mortality when compared to vancomycin-sensitive Enterococcus (VSE) bacteremia. ${ }^{53,54}$

\section{Infective endocarditis}

Enterococci are the second most common cause of infective endocarditis (IE) at 5\%-20\% of cases. ${ }^{55}$ Endocarditis caused by VRE faecalis is associated with central venous lines, liver transplantation, and mitral valve infections, whereas VRE faecium endocarditis is associated with infection of the tricuspid valve. ${ }^{56}$ The common sources for seeding originate from the GI or GU tract. ${ }^{57}$ Enterococcal endocarditis typically presents as a subacute course, with the most common clinical manifestations being the presence of a murmur, fever, weight loss, malaise, and generalized aches. ${ }^{52,58}$ Less commonly seen are peripheral signs of endocarditis such as Osler's nodes, petechiae, and Roth's spots.

\section{Intra-abdominal and pelvic infections}

As enterococci are commensals of the GI tract, it is common for them to be isolated from pelvic and intra-abdominal infections (IAIs), usually along with Gram-negative and anaerobic organisms. ${ }^{52}$ Most consider the treatment of IAIs in the immunocompromised and severely ill associated with abscesses, wounds, or peritonitis in patients with damaged heart valves as acceptable means of avoiding bacteremia or endocarditis. ${ }^{59}$ In contrast, enterococci are able to cause monomicrobial peritonitis infections, most commonly in patients undergoing chronic peritoneal dialysis or suffering from liver cirrhosis, and treatment is considered more appropriate in these settings..$^{57}$

\section{Urinary tract infections}

VRE is fast becoming a major cause of health care-associated urinary tract infections (UTIs). Enterococci account for 15\% of all catheter-associated urinary tract infections (CAUTIs), ranking second overall in the US, which is an increase from previous years when it was ranked third. ${ }^{11,49}$ They are more common in men and are usually associated with recurrent UTIs, previous antibiotic treatment, indwelling catheters, instrumentation, and abnormalities of the GU tract. ${ }^{52}$ Discerning between colonization and infection can be difficult with VRE, as it is a colonizer of the GU tract and often results in asymptomatic bacteriuria. ${ }^{60}$

\section{Central nervous system infections}

Central nervous system (CNS) infections are an extremely rare presentation for VRE. ${ }^{61}$ They typically occur in older patients with serious underlying diseases, such as hematologic malignancies, solid tumors, pulmonary disease, and cardiac disease. VRE faecium is a more typical cause of these infections compared to VRE faecalis, at $82 \%$ versus $5 \%$, respectively. Clinical manifestations include acute courses of fever, altered mental status, and rarely with coma, shock, focal CNS deficits, and petechial rash. Cerebrospinal fluid findings typically include pleocytosis, low glucose, and increased protein levels. 


\section{Skin and skin structure infections}

Enterococci are colonizers of the skin and have been associated with skin and skin structure infections (SSSIs). ${ }^{52}$ They are usually a part of polymicrobial infections, and their pathogenic role can be questioned. Enterococci are typically isolated from decubiti and diabetic foot ulcers, and rarely have been known to cause osteomyelitis, septic arthritis, and soft tissue abscesses. ${ }^{62}$

\section{Optimal management}

Treament of VRE infections can be controversial, as it commonly presents as a nonvirulent colonizer in polymicrobial infections, although serious infections such as bacteremia and IE do warrant treatment. Treatment should start with source control, as most infections represent colonization, and cure can be obtained without antibacterial therapy directed at the enterococci. ${ }^{34}$ Agents with in vitro activity against ampicillin and vancomycin-resistant enterococci with HLR to aminoglycosides are summarized in Table 3 , and potential treatment options based on indication are presented in Table 4.

\section{$\beta$-lactams and aminoglycoside synergy}

Ampicillin monotherapy should be used preferentially for any ampicillin-susceptible VRE infection that does not require bactericidal activity. For UTIs, high doses of ampicillin (18-30 g/day) or amoxicillin (500 mg every 8 hours) obtain sufficient urine concentration to make treatment of ampicillin and vancomycin-resistant Enterococcus feasible. ${ }^{35,63}$ In the rare case of a VRE faecalis $\beta$-lactamase producer, ampicillin/ sulbactam should be used.

For bacteremia caused by ampicillin-sensitive VRE, monotherapy with ampicillin is recommended, as no benefit has been found with aminoglycoside synergy ${ }^{64}$ If bactericidal activity is required for the treatment of an endovascular infection, a synergistic combination of a $\beta$-lactam with an aminoglycoside (gentamicin or streptomycin) should be used. ${ }^{18,65}$ For ampicillin and vancomycin-resistant Enterococcus without HLR to aminoglycosides, high-dose ampicillin with an aminoglycoside can be considered for a minimum inhibitory concentration (MIC) $\leq 64 \mathrm{mg} / \mathrm{L}$, as sufficient serum concentrations are obtained. ${ }^{66,67}$ For IE due to ampicillin-susceptible $E$. faecalis, ampicillin with ceftriaxone should be considered an alternative treatment option, as it has shown efficacy similar to that of ampicillin with gentamicin, but with less nephrotoxicity ${ }^{66,68}$ The mechanism for this bactericidal synergy is due to the saturation of different PBPs by each agent. ${ }^{69}$

\section{Quinupristin/dalfopristin}

Quinupristin/Dalfopristin (Q/D) is a parenteral combination of streptogramin type A (70\% dalfopristin) and type B (30\% quinupristin). It has bactericidal activity against various Gram-positive bacteria, but is bacteriostatic against VRE faecium, and lacks activity against $E$. faecalis due to efflux pumps. ${ }^{70} \mathrm{Q} / \mathrm{D}$ was approved for the treatment of VRE, but this indication was removed due to a failure to show a clinical benefit. ${ }^{71}$ Resistance to $\mathrm{Q} / \mathrm{D}$ by VRE faecium is mediated by target modification, drug inactivation, or active efflux. ${ }^{62}$ Dose-limiting toxicities of myalgias and arthralgias can lead to treatment discontinuation, and administration through a central venous catheter is required to avoid phlebitis.

For the treatment of various VRE infections, Q/D has an overall success rate of $66 \% .{ }^{72} \mathrm{Q} / \mathrm{D}$ is recommended as an option for the treatment of ampicillin and vancomycin-resistant E. faecium with HLR to aminoglycosides, but it does not have cidal activity and only anecdotal support as a monotherapy treatment in this setting. ${ }^{73} \mathrm{Q} / \mathrm{D}$ has demonstrated clinical cure for IE when administered concurrently with high-dose ampicillin or doxycycline. ${ }^{74}$ It has poor CNS penetration due to its high molecular weight, and has shown failures in the treatment of VRE CNS infections when used alone. ${ }^{75}$ Only $15 \%-19 \%$ of its active metabolites are excreted in the urine, but it has been used in the treatment of VRE UTIs with a response rate of $80 \% .{ }^{72,76}$ Due to adverse effects and treatment failures, Q/D should be considered as an alternative option for VRE infections after the use of linezolid or daptomycin.

\section{Oxazolidinones}

\section{Linezolid}

Linezolid is a parenteral and oral bacteriostatic oxazolidinone with broad-spectrum activity against Gram-positive organisms, including VRE faecalis and faecium. It is the only agent approved by the Food and Drug Administration (FDA) for the treatment of VRE infections. Resistance to linezolid is rare, but it has been described in the literature and is associated with the duration of previous linezolid therapy. ${ }^{77}$ Resistance to linezolid in VRE is a result of decreased binding due to mutations at the 23S ribosomal RNA or acquisition of a cfr (chloramphenicol-florfenicol resistance) gene through horizontal transmission, causing methylation of the $23 \mathrm{~S}$ ribosomal RNA. ${ }^{78}$

Linezolid has displayed efficacy in the treatment of VRE faecium bacteremia with an open-label, nonrandomized, compassionate-use program reporting microbiological and clinical cure rates of $85.3 \%$ and $79.0 \%$, respectively. ${ }^{79}$ Linezolid is recommended as a first-line treatment option for 
Table 3 Agents used for the treatment of serious ampicillin and vancomycin-resistant enterococcal infections with high-level resistance to aminoglycosides

\begin{tabular}{|c|c|c|c|}
\hline $\begin{array}{l}\text { Therapeutic } \\
\text { class and agent }\end{array}$ & Mechanism of action & $\begin{array}{l}\text { Dosing by FDA-approved } \\
\text { indication(s) }\end{array}$ & Dosage adjustment \\
\hline \multicolumn{4}{|l|}{ Oxazolidinone } \\
\hline Linezolid $^{116}$ & $\begin{array}{l}\text { Inhibits protein synthesis by binding } \\
\text { to the } 23 S \text { ribosomal RNA of the } \\
50 \text { S subunit }\end{array}$ & $\begin{array}{l}\text { Vancomycin-resistant Enterococcus } \\
\text { faecium infections, including } \\
\text { concurrent bacteremia; nosocomial } \\
\text { pneumonia; CAP; complicated and } \\
\text { uncomplicated SSSI: } \\
600 \mathrm{mg} \text { IV or PO every } 12 \text { hours }\end{array}$ & $\begin{array}{l}\text { For HD, normal dose, but } \\
\text { dose post-HD on HD days }\end{array}$ \\
\hline Tedizolid"19 & $\begin{array}{l}\text { Inhibits protein synthesis by binding } \\
\text { to the } 50 \text { S ribosomal subunit }\end{array}$ & $\begin{array}{l}\text { Acute bacterial SSSI: } \\
200 \text { mg IV or PO every } 24 \text { hours }\end{array}$ & None \\
\hline \multicolumn{4}{|l|}{ Streptogramin } \\
\hline $\begin{array}{l}\text { Quinupristin/ } \\
\text { dalfopristin }^{71}\end{array}$ & $\begin{array}{l}\text { Each agent acts differently with the } 50 \mathrm{~S} \\
\text { ribosome to inhibit early and late phase } \\
\text { protein synthesis }\end{array}$ & $\begin{array}{l}\text { Complicated SSSI: } \\
7.5 \mathrm{mg} / \mathrm{kg} \text { IV every } 12 \text { hours }\end{array}$ & None \\
\hline \multicolumn{4}{|c|}{ Cyclic lipopeptide } \\
\hline Daptomycin ${ }^{117}$ & $\begin{array}{l}\text { Binding to cell membrane } \\
\text { (concentration- and calcium-dependent); } \\
\text { causes rapid depolarization of the } \\
\text { membrane, inhibiting protein, DNA, } \\
\text { and RNA synthesis, leading to cell death }\end{array}$ & $\begin{array}{l}\text { Complicated SSSI: } \\
4 \mathrm{mg} / \mathrm{kg} \text { IV every } 24 \text { hours; } \\
\text { Staphylococcus aureus bacteremia, } \\
\text { including those with right-sided } \\
\text { endocarditis: } \\
6 \mathrm{mg} / \mathrm{kg} \text { IV every } 24 \text { hours (consider } \\
\text { higher dosing for severe VRE infections } \\
=8-12 \mathrm{mg} / \mathrm{kg} \text { IV every } 24 \text { hours) }\end{array}$ & $\begin{array}{l}\text { Complicated SSSI: } \\
\mathrm{CrCl}<30 \mathrm{~mL} / \mathrm{min}=4 \mathrm{mg} / \mathrm{kg} \mathrm{IV} \text { every } 48 \text { hours } \\
\mathrm{HD}=4 \mathrm{mg} / \mathrm{kg} \text { IV every } 48 \text { hours following HD } \\
\text { on } \mathrm{HD} \text { days } \\
\text { Bacteremia: } \\
\mathrm{CrCl}<30 \mathrm{~mL} / \mathrm{min}=6 \mathrm{mg} / \mathrm{kg} \mathrm{IV} \mathrm{every} 48 \text { hours } \\
\mathrm{HD}=6 \mathrm{mg} / \mathrm{kg} \mathrm{IV} \text { every } 48 \text { hours following HD } \\
\text { on } \mathrm{HD} \text { days }\end{array}$ \\
\hline \multicolumn{4}{|c|}{ 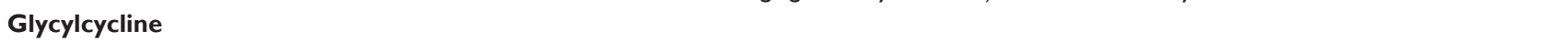 } \\
\hline Tigecycline ${ }^{1 / 8}$ & $\begin{array}{l}\text { Inhibits protein translation by binding } \\
\text { to the } 30 \mathrm{~S} \text { ribosomal subunit }\end{array}$ & $\begin{array}{l}\text { Complicated SSSI; IAI; CAP: } \\
\text { I00 mg IV loading dose, then } \\
50 \text { mg IV every I } 2 \text { hours }\end{array}$ & $\begin{array}{l}\text { Severe hepatic impairment (Child-Pugh C): } \\
\text { I00 mg IV day I, then } \\
25 \mathrm{mg} \text { IV every I } 2 \text { hours }\end{array}$ \\
\hline \multicolumn{4}{|l|}{ Lipoglycopeptide } \\
\hline Telavancin 109 & $\begin{array}{l}\text { Dual mechanism: } \\
\text { Disrupts cell wall synthesis by binding } \\
\text { to D-Ala-D-Lac of peptidoglycan, } \\
\text { preventing cross-linking } \\
\text { Disrupts membrane integrity and } \\
\text { increases cell membrane permeability, } \\
\text { causing cell lysis }\end{array}$ & $\begin{array}{l}\text { Complicated SSSI; HAP/VAP: } \\
10 \text { mg/kg IV every } 24 \text { hours }\end{array}$ & $\begin{array}{l}\mathrm{CrCl} 30-50 \mathrm{~mL} / \mathrm{min}=7.5 \mathrm{mg} / \\
\mathrm{kg} \text { every } 24 \mathrm{hours} \\
\mathrm{CrCl} 10-30 \mathrm{~mL} / \mathrm{min}=10 \mathrm{mg} / \mathrm{kg} \text { every } 48 \\
\text { hours } \\
\mathrm{CrCl}<10 \mathrm{~mL} / \mathrm{min}=\mathrm{IE} \\
\mathrm{HD}=\mathrm{IE}\end{array}$ \\
\hline Dalbavancin ${ }^{108}$ & $\begin{array}{l}\text { Disrupts cell-wall synthesis by binding } \\
\text { to D-Ala-D-Lac of peptidoglycan, } \\
\text { preventing cross-linking }\end{array}$ & $\begin{array}{l}\text { Acute bacterial SSSI: } \\
\text { I,000 mg IV on day I, then } \\
500 \mathrm{mg} \text { IV on day } 8\end{array}$ & $\begin{array}{l}\mathrm{CrCl}<30 \mathrm{~mL} / \mathrm{min} \text { and no } \\
\mathrm{HD}=750 \mathrm{mg} \text { on day } \mathrm{I}, 375 \text { on } \mathrm{mg} \text { day } 8\end{array}$ \\
\hline Oritavancin $^{120}$ & $\begin{array}{l}\text { Triple mechanism: } \\
\text { Inhibition of cell wall transglycosylation } \\
\text { by binding to D-Ala-D-Lac } \\
\text { Inhibition of cell wall transpeptidation } \\
\text { by binding to the bridging segment } \\
\text { Disruption of membrane integrity, } \\
\text { increasing permeability, causing cell lysis }\end{array}$ & $\begin{array}{l}\text { Acute bacterial SSSI: } \\
\text { I,200 mg IV once }\end{array}$ & $\begin{array}{l}\text { None (not studied in } \\
\mathrm{CrCl}<30 \mathrm{~mL} / \mathrm{min} \text { ) }\end{array}$ \\
\hline
\end{tabular}

Abbreviations: CAP, community-acquired pneumonia; D-Ala-D-Lac, D-alanine-D-lactate; aPTT, activated partial thromboplastin time; SSSI, skin and skin structure infection; IV, intravenous; PO, oral; HD, hemodialysis; UTI, urinary tract infection; IAI, intra-abdominal infection; CNS, central nervous system HAP, hospital-acquired pneumonia; VAP, ventilator-associated pneumonia; IE, insufficient evidence; GI, gastrointestinal; INR, international normalized ratio; VRE, vancomycin-resistant Enterococcus; ALT, alanine aminotransferase; FDA, Food and Drug Administration. 


\section{VRE indication(s)}

FDA approved for vancomycin-resistant Enterococcus faecium infections, including concurrent bacteremia

Bacteremia; pneumonia

Serious or life-threatening infections associated with vancomycinresistant Enterococcus faecium bacteremia

$7.5 \mathrm{mg} / \mathrm{kg}$ IV every 8 hours Complicated SSSI, UTI, IAI

Complicated SSSI, bacteremia, IE, CNS, IAI, UTI

Complicated SSSI, IAI, CNS, UTI

Complicated SSSI, pneumonia

Acute bacterial SSSI; bacteremia

Acute bacterial SSSI; bacteremia
Headache $(5.7 \%-8.8 \%)$, nausea $(5.1 \%-6.6 \%)$, vomiting ( $2 \%-4.3 \%)$, diarrhea $(8.2 \%-8.3 \%)$, serotonin syndrome, lactic acidosis Duration related: optic neuritis, peripheral neuropathy, myelosuppression

Diarrhea (4.0\%), nausea (8.0\%), vomiting (3.0\%), headache $(6.0 \%)$, thrombocytopenia (2.3\%), neutropenia $(0.5 \%)$

Injection site reactions: edema (17.3\%), inflammation (42.0\%), pain (40.0\%), rash (2.5\%) Asymptomatic hyperbilirubinemia ( $0.9 \%$ to $25 \%$ ), dose and/or frequency related arthralgias and myalgias (3.3\% to $47 \%$ )

Myopathy (especially with higher dose and/or concurrent HMG-CoA reductase inhibitor therapy), neuropathy, acute eosinophilic pneumonia

Nausea (24\% to $35 \%$ ), vomiting (16\% to $20 \%$ ), acute pancreatitis

Taste disturbance (33\%), foamy urine (13\%), renal impairment (5\%), GI disturbance (5\%-27\%), QT prolongation (8\%)

Constipation (18.2\%), diarrhea (4.4\%), nausea $(5.5 \%)$, headache $(4.7 \%)$, anaphylactoid reactions $(<2 \%)$, "Red-Man syndrome" with rapid infusion ( $<30$ minutes)

Nausea (9.9\%), vomiting (4.6\%), headache (7.I\%), arm abscesses (3.8\%), asymptomatic ALT elevations (2.8\%), hypersensitivity $(<1.5 \%)$ infusion site reactions (slow or stop infusion to abate)

\section{Comments}

- Bacteriostatic;

- Nonselective monoamine oxidase inhibitor; Avoid use with serotonergic agents;

- Myelosuppression with duration >2 weeks

- Bacteriostatic;

- Weaker monoamine oxidase inhibitor than linezolid;

- Extent of myelosuppression not fully elucidated due to short study durations

- Bacteriostatic;

- No activity against $E$. faecalis;

- Inhibitor of liver enzymes

- Concentration-dependent bactericidal activity;

- Inactivated by pulmonary surfactant (avoid use for primary pulmonary infections)
- Bacteriostatic;

- Avoid in pregnancy (Class D) and for pediatric patients;

- Low blood concentrations, avoid use in bacteremia;

- Increased mortality with VAP treatment

- Concentration-dependent bactericidal activity (static against VRE expressing VanB);

- Only active against VRE expressing VanB;

- Higher nephrotoxicity compared to vancomycin;

- Black box warning: increased mortality in moderate or severe renal impairment;

- Avoid in pregnancy (class C, animal studies demonstrate fetal harm)

- Concentration-dependent bactericidal activity;

- Only active against VRE expressing VanB;

- Increased risk of hypersensitivity with a history of glycopeptide sensitivity has been noted

- Concentration-dependent bactericidal activity;

- Falsely elevated aPTT and INR post-infusion;

- Weak inducer and inhibitor of liver enzymes 
Table 4 Suggested regimens for the treatment of serious ampicillin and vancomycin-resistant enterococcal infections with high-level resistance to aminoglycosides

\begin{tabular}{|c|c|c|}
\hline $\begin{array}{l}\text { Infection } \\
\text { type }\end{array}$ & $\begin{array}{l}\text { Therapeutic } \\
\text { regimen }\end{array}$ & Comments \\
\hline \multicolumn{3}{|l|}{ Bacteremia } \\
\hline \multirow[t]{2}{*}{ Preferred } & Linezolid & \\
\hline & Daptomycin & - Consider 8-12 mg/kg/day \\
\hline \multirow[t]{2}{*}{ Alternatives } & Q/D & - Only active against $E$. faecium \\
\hline & $\begin{array}{l}\text { Daptomycin } \\
\text { combination }\end{array}$ & $\begin{array}{l}\text { Combine with either HD } \\
\text { ampicillin, ceftaroline, } \\
\text { ceftobiprole, or tigecycline }\end{array}$ \\
\hline \multicolumn{3}{|c|}{ Infective endocarditis } \\
\hline Preferred & Daptomycin & - Consider 8-12 mg/kg/day \\
\hline \multirow[t]{3}{*}{ Alternatives } & Q/D & - Only active against $E$. faecium \\
\hline & $\begin{array}{l}\text { Daptomycin } \\
\text { combination }\end{array}$ & $\begin{array}{l}\text { Combine with either HD } \\
\text { ampicillin, ceftaroline, } \\
\text { ceftobiprole, or tigecycline }\end{array}$ \\
\hline & Linezolid & \\
\hline \multicolumn{3}{|c|}{ Central nervous system } \\
\hline \multirow[t]{2}{*}{ Preferred } & Linezolid & \\
\hline & Daptomycin & $\begin{array}{l}\text { - } \pm \text { concurrent intrathecal/ } \\
\text { intraventricular administration }\end{array}$ \\
\hline \multirow[t]{3}{*}{ Alternatives } & $\mathrm{Q} / \mathrm{D}$ & - $\mathrm{Q} / \mathrm{D}+$ daptomycin is an option \\
\hline & & $\begin{array}{l}\text { - } \pm \text { concurrent intrathecal/ } \\
\text { intraventricular administration } \\
\text { - Only active against } E \text {. faecium }\end{array}$ \\
\hline & Tigecycline & \\
\hline \multicolumn{3}{|c|}{ Intra-abdominal } \\
\hline \multirow[t]{3}{*}{ Preferred } & Linezolid & \\
\hline & Daptomycin & $\begin{array}{l}\text { - Intraperitoneal administration } \\
\text { is an option }\end{array}$ \\
\hline & Tigecycline & \\
\hline Alternatives & $\mathrm{Q} / \mathrm{D}$ & - Only active against $E$. faecium \\
\hline \multicolumn{3}{|c|}{ Skin and skin structure } \\
\hline \multirow[t]{2}{*}{ Preferred } & Linezolid & - Oral option \\
\hline & Daptomyci & \\
\hline \multirow[t]{5}{*}{ Alternatives } & Tedizolid & - Oral option \\
\hline & Oritavancin & \\
\hline & Dalbavancin & - Only active against $\operatorname{VanB}$ \\
\hline & Telavancin & - Only active against $\operatorname{VanB}$ \\
\hline & $\mathrm{Q} / \mathrm{D}$ & - Only active against $E$. faecium \\
\hline \multicolumn{3}{|c|}{ Urinary tract } \\
\hline \multirow[t]{3}{*}{ Preferred } & Nitrofurantoin & - Only for uncomplicated UTI \\
\hline & Fosfomycin & - Only for uncomplicated UTI \\
\hline & Linezolid & $\begin{array}{l}\text { - } \pm \text { concurrent bladder irrigation } \\
\text { with linezolid } \\
\text { - Oral option }\end{array}$ \\
\hline \multirow[t]{4}{*}{ Alternatives } & Daptomycin & \\
\hline & HD ampicillin & \\
\hline & or amoxicillin & \\
\hline & $\mathrm{Q} / \mathrm{D}$ & - Only active against $E$. faecium \\
\hline
\end{tabular}

Abbreviations: UTI, urinary tract infection; HD, high-dose; Q/D, Quinupristin/ dalfopristin.

IE due to ampicillin and vancomycin-resistant enterococci with HLR to aminoglycosides, but it is not bactericidal. ${ }^{73}$ It has successfully treated several VRE IE cases, but treatment failures have also been reported. ${ }^{39,80}$ Linezolid has good urine penetration at roughly $40 \%$, but this decreases dramatically in renal dysfunction. ${ }^{81}$ In the case of renal dysfunction, it can be administered via bladder irrigation. ${ }^{82}$ Linezolid has good penetration into the CNS at roughly $70 \%$ and has been used successfully as monotherapy for VRE CNS infections. ${ }^{75,83} \mathrm{As}$ the only agent approved for the treatment of VRE infections, linezolid is a preferred agent in the settings of bacteremia, UTI, CNS infection, IAI, and SSSI, but should be considered an alternative option for IE where it lacks bactericidal activity.

\section{Tedizolid}

Tedizolid is a next-generation parenteral and oral oxazolidinone with a broad spectrum of bacteriostatic activity against resistant Gram-positive bacteria including both VanA and VanB VRE. ${ }^{84}$ Against VRE, tedizolid has a fourfold lower MIC when compared to linezolid, and has activity against linezolid-resistant strains with a $c$ fr mutation. ${ }^{85}$ This increased potency is thought to be due to additional interactions with the ribosomal subunit of Gram-positive bacteria. ${ }^{86}$ It has been approved for the treatment of acute bacterial SSSIs, and is currently undergoing clinical trials for the treatment of bacteremia and pneumonia. With more potent activity against VRE compared to linezolid, tedizolid has the potential to be a first-line agent for the treatment of serious VRE infections.

\section{Daptomycin}

Daptomycin is a cyclic lipopeptide with rapid concentrationdependent bactericidal activity against many resistant Grampositive organisms, including VRE faecalis and faecium. Two recent meta-analyses comparing daptomycin to linezolid for the treatment of VRE bacteremia found higher mortality in patients treated with daptomycin compared to linezolid. However, these studies are limited by heterogeneity, variable daptomycin dosing, and selection bias for daptomycin use in those with hematological abnormalities ${ }^{87,88}$ Both linezolid and daptomycin should still be used as first-line options for the treatment of VRE bacteremia, but high-dose daptomycin use should be considered $(8-12 \mathrm{mg} / \mathrm{kg})$.

Treatment failures and resistance development while using daptomycin monotherapy for enterococcal endocarditis have led to studies into combination therapies and the use of highdose daptomycin at $8-12 \mathrm{mg} / \mathrm{kg} /$ day. ${ }^{89}$ High-dose daptomycin may be of clinical benefit to reach the higher MICs required for bactericidal activity against Enterococcus, to increase the free fraction of drug as it is highly protein bound, and to avoid resistance. ${ }^{52,90,91}$ Daptomycin resistance is associated with longer durations of therapy and is a function of genetic mutations in the genes responsible for biogenesis, permeability, and cell membrane potential. Daptomycin dosed up to $12 \mathrm{mg} / \mathrm{kg}$ has proven safe and well-tolerated by patients. ${ }^{92} \mathrm{~A}$ recent retrospective multicenter study assessed the efficacy of high-dose 
daptomycin at a median dose of $8.2 \mathrm{mg} / \mathrm{kg}$ for the treatment of VRE, with an overall clinical success rate of $89 \%$ and microbiological eradication achieved in $93 \%$ of patients. ${ }^{93}$

Daptomycin achieves poor CNS penetration at 5\%-6\% with inflamed meninges; therefore, monotherapy for CNS infections is not advised..$^{75}$ There have been successful case reports with intravesicular administration of daptomycin and combination therapy of daptomycin plus linezolid, gentamicin, or Q/D for VRE meningitis reported in the literature. ${ }^{75}$ Daptomycin administered intraventricularly along with systemic linezolid was successful for the treatment of a CNS infection due to VRE. ${ }^{94}$ Daptomycin is a treatment option for IAIs and has been administered intraperitoneally for successful treatment of VRE peritonitis. ${ }^{95}$ It achieves high renal clearance at $50 \%-70 \%$, giving it a favorable profile for the treatment of VRE UTIs. ${ }^{96}$ Daptomycin is a preferred agent for the treatment of bacteremia, IE, UTI, CNS infection, IAI, and SSSI, but higher doses should be considered for the treatment of serious VRE infections, and synergy with a $\beta$-lactam can be attempted for refractory cases.

\section{Daptomycin and $\beta$-lactam synergy}

Recent in vitro studies and a case report have shown synergy for combinations of daptomycin and various $\beta$-lactams in VRE, including the new-generation cephalosporins ceftaroline and ceftobiprole (Table 5). ${ }^{97-102}$ These combinations increase daptomycin's bactericidal activity and reduce resistance formation in VRE faecalis and faecium. The mechanism of synergy is due to decreased net positive bacterial surface charge, allowing for increased binding affinity of the daptomycin cationic complex to the cytoplasmic membrane, thereby increasing activity. Although promising, this combination therapy is best saved as an alternative treatment regimen for serious VRE infections until further studies are performed in vivo.

\section{Tigecycline}

Tigecycline is a glycylcycline, a derivative of minocycline with a functional group substitution, allowing activity against tetracycline-resistant Gram-positive and Gram-negative organisms including VRE faecalis and faecium. ${ }^{103}$ Resistance to tigecycline in VRE has not been reported yet.

The CNS penetration of tigecycline is not fully elucidated; therefore, its use for the treatment of VRE CNS infections is undetermined. Tigecycline has roughly $22 \%$ renal excretion, which exceeds the $\mathrm{MIC}_{90}$ of VRE, but clinical data is lacking to support the use of tigecycline for the treatment of UTIs. ${ }^{104}$ No quality studies have been performed to assess the efficacy of tigecycline monotherapy for the treatment of IE, but it has been used successfully along with daptomycin for the treatment of IE due to VRE. ${ }^{105}$ Tigecycline should not be used for the treatment of VRE bacteremia due to a high volume of distribution (7-17 L/kg) causing low levels in serum. ${ }^{103}$ Tigecycline achieves high penetration into the peritoneal space at roughly $50 \%$ and has a broad spectrum of activity, making it an ideal option for the treatment of IAI involving VRE. ${ }^{106}$ Tigecycline can be considered a preferred treatment for polymicrobial IAIs associated with VRE, should not be used for VRE bacteremias due to low serum concentrations, and is lacking in clinical data to support its use for other indications.

\section{Lipoglycopeptides}

Lipoglycopeptides are parenteral semisynthetic glycopeptides that contain lipophilic side chains to increase their half-life and allow for anchoring to the cell membrane of Gram-positive bacteria, enhancing their activity. ${ }^{107}$

\section{Telavancin and dalbavancin}

Telavancin and dalbavancin exhibit concentration-dependent bactericidal activity against various resistant Gram-positive bacteria including VRE expressing VanB, with little to no activity against VanA expressing VRE. ${ }^{108,109}$ Telavancin was approved for the treatment of complicated SSSI in 2009, and for hospital-acquired pneumonia (HAP) and ventilatorassociated pneumonia (VAP) in 2013. Dalbavancin was approved for the treatment of acute bacterial SSSI in 2014 and is currently undergoing clinical trials for the treatment of bacteremia. Both represent treatment options for cABSSI caused by VanB expressing VRE, and dalbavancin could potentially be used for VRE bacteremia, although the usefulness of this is questionable given that most VRE express VanA resistance.

\section{Oritavancin}

Oritavancin has the broadest spectrum of the lipoglycopeptides having bactericidal activity against almost all resistant Gram-positive bacteria including both VanA and VanB expressing VRE. ${ }^{110}$ It is able to bind to the D-Ala-D-Lac that is produced by VanA. An extended half-life reduces its post-antibiotic effect and opens the possibility for mutant formation. ${ }^{107}$ In a rabbit IE model, oritavancin was able to effect a significant reduction in bacterial counts but also selected for mutant formation; however, no resistance was seen when oritavancin was combined with gentamicin for synergy. ${ }^{111}$ It has been approved for the treatment of acute bacterial SSSIs and is currently undergoing clinical trials for the treatment of bacteremia. Oritavancin represents a promising option for the treatment of VRE SSSIs and possibly 


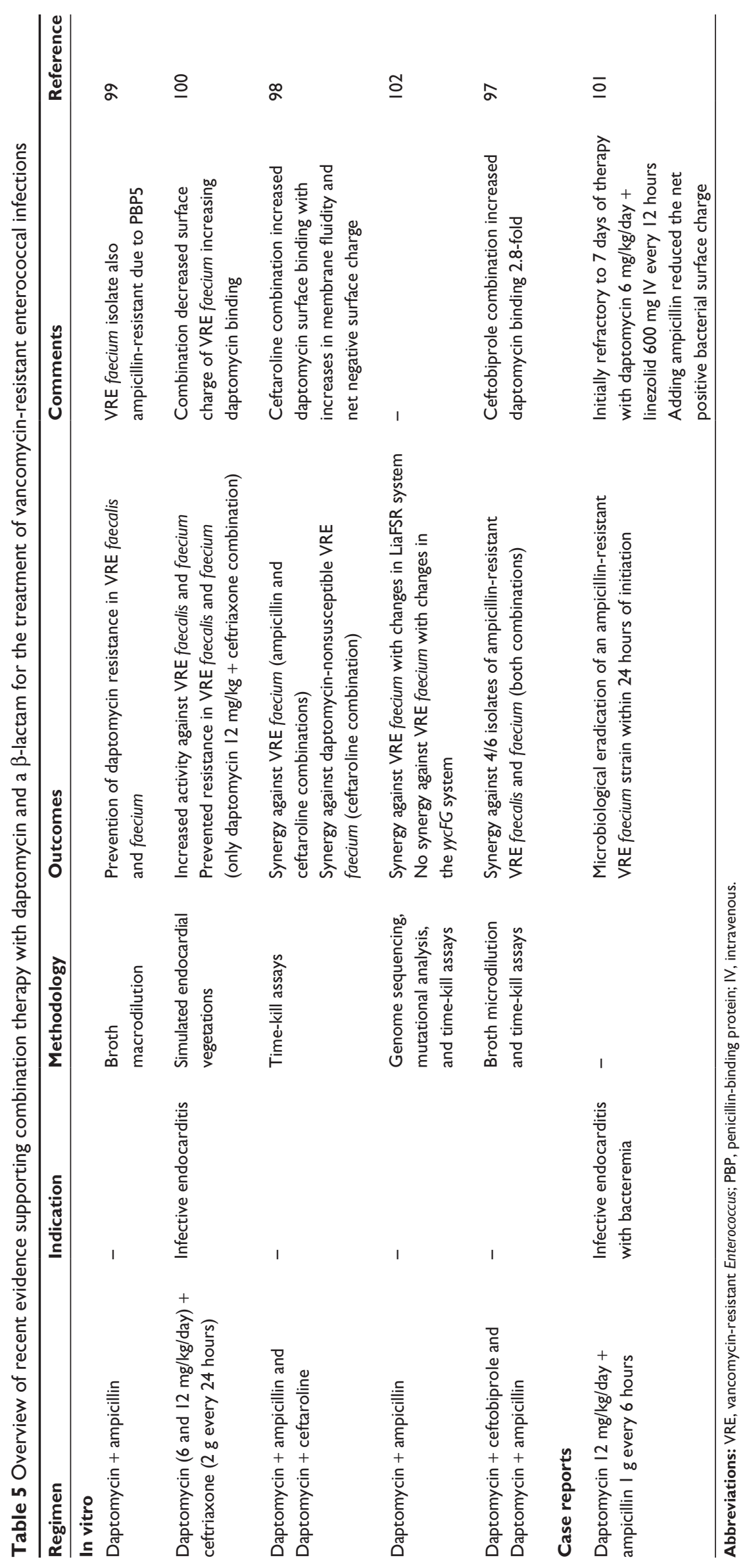


bacteremia or even endocarditis, when administered with gentamicin for synergy.

\section{Other antienterococcal agents}

For the treatment of uncomplicated UTIs caused by ampicillin and vancomycin-resistant Enterococcus, nitrofurantoin and fosfomycin should be considered as preferred therapies. Both have good activity against VRE and favorable pharmacokinetic profiles for the treatment of uncomplicated UTIs. ${ }^{112,113}$ Both can be considered as first-line treatments for uncomplicated UTIs caused by VRE, but are not recommended for the treatment of complicated UTIs.

Chloramphenicol is a bacteriostatic agent that was used in the past for VRE treatment, but it is not used often anymore due to lack of availability, clinical failures, development of resistance, and hematologic toxicity. ${ }^{114}$

\section{Conclusion}

VRE has become a major nosocomial pathogen worldwide due to its colonization strategy, persistence in the environment, and genome plasticity. Infections typically present in the immunosuppressed, where virulence is variable, and clinical manifestations include bacteremia, IE, pelvic and IAIs, UTIs, SSSIs, and rarely CNS infections. A lack of randomized controlled trials assessing the efficacy of limited treatment options have made therapy difficult, but new agents, combination therapies, and improved dosing strategies have broadened the practitioner's armamentarium and hold promise for the future treatment of VRE.

\section{Disclosure}

The authors report no conflicts of interest in this work. The views expressed in this review article are solely those of the authors and do not necessarily reflect the views of the Chicago College of Pharmacy or Rush Copley Medical Center.

\section{References}

1. Leclercq R, Derlot E, Duval J, Courvalin P. Plasmid-mediated resistance to vancomycin and teicoplanin in Enterococcus faecium. N Engl J Med. 1988;319(3):157-161.

2. Uttley AH, Collins $\mathrm{CH}$, Naidoo J, George RC. Vancomycin-resistant enterococci. Lancet. 1988;1(8575-6):57-58.

3. Sahm DF, Kissinger J, Gilmore MS, et al. In vitro susceptibility studies of vancomycin-resistant Enterococcus faecalis. Antimicrob Agents Chemother. 1989;33(9):1588-1591.

4. Acar J, Casewell M, Freeman J, Friis C, Goossens H. Avoparcin and virginiamycin as animal growth promoters: a plea for science in decision-making. Clin Microbiol Infect. 2000;6(9):477-482.

5. Kirst HA, Thompson DG, Nicas TI. Historical yearly usage of vancomycin. Antimicrob Agents Chemother. 1998;42(5):1303-1304.

6. Bonten MJ, Willems R, Weinstein RA. Vancomycin-resistant enterococci: why are they here, and where do they come from? Lancet Infect Dis. 2001;1(5):314-325.
7. FriedenTR, Munsiff SS, Low DE, et al. Emergence of vancomycin-resistant enterococci in New York City. Lancet. 1993;342(8863):76-79.

8. The European Antimicrobial Resistance Surveillance System. EARS-Net Results; 2015; Available from: http://www.ecdc.europa.eu/ en/healthtopics/antimicrobial_resistance/database/Pages/database.aspx. Accessed January 1, 2015

9. Chang S, Sievert DM, Hageman JC, et al. Infection with vancomycinresistant Staphylococcus aureus containing the vanA resistance gene. N Engl J Med. 2003;348(14):1342-1347.

10. Euzéby JP. List of Prokaryotic Names with Standing in NomenclatureGenus Enterococcus; 2015. Available from: http://www.bacterio.net/ enterococcus.html. Accessed February 17, 2015.

11. Sievert DM, Ricks P, Edwards JR, et al; National Healthcare Safety Network (NHSN) Team and Participating NHSN Facilities. Antimicrobial-resistant pathogens associated with healthcare-associated infections: summary of data reported to the National Healthcare Safety Network at the Centers for Disease Control and Prevention, 2009-2010. Infect Control Hosp Epidemiol. 2013;34(1):1-14.

12. French GL. Enterococci and vancomycin resistance. Clin Infect Dis 1998;27(Suppl 1):S75-S83.

13. Zirakzadeh A, Patel R. Vancomycin-resistant enterococci: colonization, infection, detection, and treatment. Mayo Clin Proc. 2006;81(4): 529-536.

14. Cattoir V, Leclercq R. Twenty-five years of shared life with vancomycin-resistant enterococci: is it time to divorce? J Antimicrob Chemother. 2013;68(4):731-742.

15. Moellering RC Jr. The Garrod lecture. The Enterococcus: a classic example of the impact of antimicrobial resistance on therapeutic options. J Antimicrob Chemother. 1991;28(1):1-12.

16. Murray BE. Vancomycin-resistant enterococci. Am J Med. 1997;102(3): 284-293.

17. Moellering RC Jr, Weinberg AN. Studies on antibiotic syngerism against enterococci. II. Effect of various antibiotics on the uptake of 14 C-labeled streptomycin by enterococci. J Clin Invest. 1971;50(12): 2580-2584.

18. Arias CA, Contreras GA, Murray BE. Management of multidrug-resistant enterococcal infections. Clin Microbiol Infect. 2010;16(6):555-562.

19. Rybkine T, Mainardi JL, Sougakoff W, Collatz E, Gutmann L. Penicillin-binding protein 5 sequence alterations in clinical isolates of Enterococcus faecium with different levels of beta-lactam resistance. J Infect Dis. 1998;178(1):159-163.

20. Murray BE. Diversity among multidrug-resistant enterococci. Emerg Infect Dis. 1998;4(1):37-47.

21. Murray BE. Beta-lactamase-producing enterococci. Antimicrob Agents Chemother. 1992;36(11):2355-2359.

22. Horodniceanu T, Bougueleret L, El-Solh N, Bieth G, Delbos F. High-level, plasmid-borne resistance to gentamicin in Streptococcus faecalis subsp. zymogenes. Antimicrob Agents Chemother. 1979;16(5): 686-689.

23. Mederski-Samoraj BD, Murray BE. High-level resistance to gentamicin in clinical isolates of enterococci. J Infect Dis. 1983;147(4):751-757.

24. Eliopoulos GM. Aminoglycoside resistant enterococcal endocarditis. Infect Dis Clin North Am. 1993;7(1):117-133.

25. Mainardi JL, Villet R, Bugg TD, Mayer C, Arthur M. Evolution of peptidoglycan biosynthesis under the selective pressure of antibiotics in Gram-positive bacteria. FEMS Microbiol Rev. 2008;32(2): 386-408.

26. Walsh C. Molecular mechanisms that confer antibacterial drug resistance. Nature. 2000;406(6797):775-781.

27. Courvalin P. Vancomycin resistance in Gram-positive cocci. Clin Infect Dis. 2006;42(Suppl 1):S25-S34.

28. Boyd DA, Willey BM, Fawcett D, Gillani N, Mulvey MR. Molecular characterization of Enterococcus faecalis N06-0364 with low-level vancomycin resistance harboring a novel D-Ala-D-Ser gene cluster, vanL. Antimicrob Agents Chemother. 2008;52(7):2667-2672.

29. Lebreton F, Depardieu F, Bourdon N, et al. D-Ala-d-Ser VanN-type transferable vancomycin resistance in Enterococcus faecium. Antimicrob Agents Chemother. 2011;55(10):4606-4612. 
30. McKessar SJ, Berry AM, Bell JM, Turnidge JD, Paton JC. Genetic characterization of vanG, a novel vancomycin resistance locus of Enterococcus faecalis. Antimicrob Agents Chemother. 2000;44(11): 3224-3228.

31. Xu X, Lin D, Yan G, et al. vanM, a new glycopeptide resistance gene cluster found in Enterococcus faecium. Antimicrob Agents Chemother. 2010;54(11):4643-4647.

32. Fisher K, Phillips C. The ecology, epidemiology and virulence of Enterococcus. Microbiology. 2009;155(pt 6):1749-1757.

33. Werner G, Coque TM, Hammerum AM, et al. Emergence and spread of vancomycin resistance among enterococci in Europe. Euro Surveill. 2008;13(47):19046.

34. Linden PK. Optimizing therapy for vancomycin-resistant enterococci (VRE). Semin Respir Crit Care Med. 2007;28(6):632-645.

35. Cetinkaya Y, Falk P, Mayhall CG. Vancomycin-resistant enterococci. Clin Microbiol Rev. 2000;13(4):686-707.

36. Baden LR, Critchley IA, Sahm DF, et al. Molecular characterization of vancomycin-resistant enterococci repopulating the gastrointestinal tract following treatment with a novel glycolipodepsipeptide, ramoplanin. $J$ Clin Microbiol. 2002;40(4):1160-1163.

37. Bonten MJ, Hayden MK, Nathan C, Rice TW, Weinstein RA. Stability of vancomycin-resistant enterococcal genotypes isolated from long-term-colonized patients. J Infect Dis. 1998;177(2):378-382.

38. Snyder GM, Thom KA, Furuno JP, et al. Detection of methicillinresistant Staphylococcus aureus and vancomycin-resistant enterococci on the gowns and gloves of healthcare workers. Infect Control Hosp Epidemiol. 2008;29(7):583-589.

39. Noskin GA, Siddiqui F, Stosor V, Kruzynski J, Peterson LR. Successful treatment of persistent vancomycin-resistant Enterococcus faecium bacteremia with linezolid and gentamicin. Clin Infect Dis. 1999;28(3): 689-690.

40. Kramer A, Schwebke I, Kampf G. How long do nosocomial pathogens persist on inanimate surfaces? A systematic review. BMC Infect Dis. 2006;6:130.

41. Vergis EN, Hayden MK, Chow JW, et al. Determinants of vancomycin resistance and mortality rates in enterococcal bacteremia. A prospective multicenter study. Ann Intern Med. 2001;135(7):484-492.

42. Furtado GH, Mendes RE, Pignatari AC, Wey SB, Medeiros EA. Risk factors for vancomycin-resistant Enterococcus faecalis bacteremia in hospitalized patients: an analysis of two case-control studies. Am J Infect Control. 2006;34(7):447-451.

43. Zacharioudakis IM, Zervou FN, Ziakas PD, Rice LB, Mylonakis E. Vancomycin-resistant enterococci colonization among dialysis patients: a meta-analysis of prevalence, risk factors, and significance. Am J Kidney Dis. 2015;65(1):88-97.

44. Papadimitriou-Olivgeris M, Drougka E, Fligou F, et al. Risk factors for enterococcal infection and colonization by vancomycin-resistant enterococci in critically ill patients. Infection. 2014;42(6):1013-1022.

45. Van der Auwera P, Pensart N, Korten V, Murray BE, Leclercq R. Influence of oral glycopeptides on the fecal flora of human volunteers: selection of highly glycopeptide-resistant enterococci. J Infect Dis. 1996;173(5):1129-1136.

46. Ghanem G, Hachem R, Jiang Y, Chemaly RF, Raad I. Outcomes for and risk factors associated with vancomycin-resistant Enterococcus faecalis and vancomycin-resistant Enterococcus faecium bacteremia in cancer patients. Infect Control Hosp Epidemiol. 2007;28(9):1054-1059.

47. Tornieporth NG, Roberts RB, John J, Hafner A, Riley LW. Risk factors associated with vancomycin-resistant Enterococcus faecium infection or colonization in 145 matched case patients and control patients. Clin Infect Dis. 1996;23(4):767-772.

48. Fridkin SK, Edwards JR, Courval JM, et al; Intensive Care Antimicrobial Resistance Epidemiology (ICARE) Project; The National Nosocomial Infections Surveillance (NNIS) System Hospitals. The effect of vancomycin and third-generation cephalosporins on prevalence of vancomycin-resistant enterococci in 126 US adult intensive care units. Ann Intern Med. 2001;135(3):175-183.
49. Hidron AI, Edwards JR, Patel J, et al; National Healthcare Safety Network Team; Participating National Healthcare Safety Network Facilities. NHSN annual update: antimicrobial-resistant pathogens associated with healthcare-associated infections: annual summary of data reported to the National Healthcare Safety Network at the Centers for Disease Control and Prevention, 2006-2007. Infect Control Hosp Epidemiol. 2008;29(11):996-1011.

50. Zhanel GG, Adam HJ, Baxter MR, et al; Canadian Antimicrobial Resistance Alliance. Antimicrobial susceptibility of 22746 pathogens from Canadian hospitals: results of the CANWARD 2007-2011 study. J Antimicrob Chemother. 2013;68(Suppl 1):i7-i22.

51. Garrison RN, Fry DE, Berberich S, Polk HC Jr. Enterococcal bacteremia: clinical implications and determinants of death. Ann Surg. 1982; 196(1):43-47.

52. Arias CA, Murray BE. Enterococcus species, Streptococcus gallolyticus group, and Leucomonstoc species. In: Bennett JE, Dolin R, Blaser MJ, editors. Mandell, Douglas, and Bennett's Principles and Practice of Infectious Diseases. Philadelphia: Saunders; 2015:2328-2339.

53. DiazGranados CA, Zimmer SM, Klein M, Jernigan JA. Comparison of mortality associated with vancomycin-resistant and vancomycinsusceptible enterococcal bloodstream infections: a meta-analysis. Clin Infect Dis. 2005;41(3):327-333.

54. Salgado CD. The risk of developing a vancomycin-resistant Enterococcus bloodstream infection for colonized patients. Am J Infect Control. 2008;36(10):S175. e5-e8.

55. Hill EE, Herijgers P, Claus P, Vanderschueren S, Herregods MC, Peetermans WE. Infective endocarditis: changing epidemiology and predictors of 6-month mortality: a prospective cohort study. Eur Heart J. 2007;28(2):196-203.

56. Forrest GN, Arnold RS, Gammie JS, Gilliam BL. Single center experience of a vancomycin resistant enterococcal endocarditis cohort. $J$ Infect. 2011;63(6):420-428.

57. Murray BE. The life and times of the Enterococcus. Clin Microbiol Rev. 1990;3(1):46-65.

58. Fernandez Guerrero ML, Goyenechea A, Verdejo C, Roblas RF, de Gorgolas M. Enterococcal endocarditis on native and prosthetic valves: a review of clinical and prognostic factors with emphasis on hospitalacquired infections as a major determinant of outcome. Medicine. 2007; 86(6):363-377.

59. Harbarth S, Uckay I. Are there patients with peritonitis who require empiric therapy for Enterococcus? Eur J Clin Microbiol Infect Dis. 2004;23(2):73-77.

60. Gupta K, Bhadelia N. Management of urinary tract infections from multidrug-resistant organisms. Infect Dis Clin North Am. 2014;28(1): 49-59.

61. Wang JS, Muzevich K, Edmond MB, Bearman G, Stevens MP. Central nervous system infections due to vancomycin-resistant enterococci: case series and review of the literature. Int $J$ Infect Dis. 2014;25: 26-31.

62. Agudelo Higuita NI, Huycke MM. Enterococcal disease, epidemiology, and implications for treatment. In: Gilmore MS, Clewell DB, Ike Y, et al., editors. Enterococci: From Commensals to Leading Causes of Drug Resistant Infection [Internet]. Boston: Massachusetts Eye and Ear Infirmary; 2014:1-27. Available from: http://www.ncbi.nlm.nih. gov/books/NBK190429/. Accessed January 1, 2015.

63. Williamson JC, Craft DW, Butts JD, Raasch RH. In vitro assessment of urinary isolates of ampicillin-resistant enterococci. Ann Pharmacother. 2002;36(2):246-250.

64. Watanakunakorn C, Patel R. Comparison of patients with enterococcal bacteremia due to strains with and without high-level resistance to gentamicin. Clin Infect Dis. 1993;17(1):74-78.

65. Krogstad DJ, Pargwette AR. Defective killing of enterococci: a common property of antimicrobial agents acting on the cell wall. Antimicrob Agents Chemother. 1980;17(6):965-968.

66. Murray BE. Vancomycin-resistant enterococcal infections. $N$ Engl J Med. 2000;342(10):710-721. 
67. Dodge RA, Daly JS, Davaro R, Glew RH. High-dose ampicillin plus streptomycin for treatment of a patient with severe infection due to multiresistant enterococci. Clin Infect Dis. 1997;25(5): 1269-1270.

68. Fernández-Hidalgo N, Almirante B, Gavaldà J, et al. Ampicillin plus ceftriaxone is as effective as ampicillin plus gentamicin for treating Enterococcus faecalis infective endocarditis. Clin Infect Dis. 2013; 56(9):1261-1268.

69. Mainardi JL, Gutmann L, Acar JF, Goldstein FW. Synergistic effect of amoxicillin and cefotaxime against Enterococcus faecalis. Antimicrob Agents Chemother. 1995;39(9):1984-1987.

70. Singh KV, Weinstock GM, Murray BE. An Enterococcus faecalis ABC homologue (Lsa) is required for the resistance of this species to clindamycin and quinupristin-dalfopristin. Antimicrob Agents Chemother. 2002;46(6):1845-1850.

71. Synercid ${ }^{\mathbb{}}$ IV (quinupristin/dalfopristin) [package insert]. New York, NY: Pfizer Inc.; 2013.

72. Linden PK, Moellering RC, Wood CA, et al; Synercid EmergencyUse Study Group. Treatment of vancomycin-resistant Enterococcus faecium infections with quinupristin/dalfopristin. Clin Infect Dis. 2001;33(11):1816-1823.

73. Baddour LM, Wilson WR, Bayer AS, et al; Committee on Rheumatic Fever, Endocarditis, and Kawasaki Disease; Council on Cardiovascular Disease in the Young; Councils on Clinical Cardiology, Stroke, and Cardiovascular Surgery and Anesthesia; American Heart Association; Infectious Diseases Society of America. Infective endocarditis: diagnosis, antimicrobial therapy, and management of complications: a statement for healthcare professionals from the Committee on Rheumatic Fever, Endocarditis, and Kawasaki Disease, Council on Cardiovascular Disease in the Young, and the Councils on Clinical Cardiology, Stroke, and Cardiovascular Surgery and Anesthesia, American Heart Association: endorsed by the Infectious Diseases Society of America. Circulation. 2005;111(23):e394-e434.

74. Brown J, Freeman BB 3rd. Combining quinupristin/dalfopristin with other agents for resistant infections. Ann Pharmacother. 2004;38(4): 677-685.

75. Knoll BM, Hellmann M, Kotton CN. Vancomycin-resistant Enterococcus faecium meningitis in adults: case series and review of the literature. Scand J Infect Dis. 2013;45(2):131-139.

76. Dever LL, Smith SM, Dejesus D, et al. Treatment of vancomycinresistant Enterococcus faecium infections with an investigational streptogramin antibiotic (quinupristin/dalfopristin): a report of fifteen cases. Microb Drug Resist. 1996;2(4):407-413.

77. Scheetz MH, Knechtel SA, Malczynski M, Postelnick MJ, Qi C. Increasing incidence of linezolid-intermediate or -resistant, vancomycin-resistant Enterococcus faecium strains parallels increasing linezolid consumption. Antimicrob Agents Chemother. 2008;52(6): 2256-2259.

78. Diaz L, Kiratisin P, Mendes RE, Panesso D, Singh KV, Arias CA. Transferable plasmid-mediated resistance to linezolid due to $\mathrm{cfr}$ in a human clinical isolate of Enterococcus faecalis. Antimicrob Agents Chemother. 2012;56(7):3917-3922.

79. Birmingham MC, Rayner CR, Meagher AK, Flavin SM, Batts DH, Schentag JJ. Linezolid for the treatment of multidrug-resistant, Grampositive infections: experience from a compassionate-use program. Clin Infect Dis. 2003;36(2):159-168.

80. Tsigrelis C, Singh KV, Coutinho TD, Murray BE, Baddour LM. Vancomycin-resistant Enterococcus faecalis endocarditis: linezolid failure and strain characterization of virulence factors. J Clin Microbiol. 2007;45(2):631-635.

81. Borner K, Borner E, Lode H. Determination of linezolid in human serum and urine by high-performance liquid chromatography. Int $J$ Antimicrob Agents. 2001;18(3):253-258.

82. Hill DM, Wood GC, Hickerson WL. Linezolid bladder irrigation as adjunctive treatment for a vancomycin-resistant Enterococcus faecium catheter-associated urinary tract infection. Ann Pharmacother. 2015; 49(2):250-253.
83. Myrianthefs P, Markantonis SL, Vlachos K, et al. Serum and cerebrospinal fluid concentrations of linezolid in neurosurgical patients. Antimicrob Agents Chemother. 2006;50(12):3971-3976.

84. Rybak JM, Marx K, Martin CA. Early experience with tedizolid: clinical efficacy, pharmacodynamics, and resistance. Pharmacotherapy. 2014; 34(11):1198-1208.

85. Brown SD, Traczewski MM. Comparative in vitro antimicrobial activities of torezolid (TR-700), the active moiety of a new oxazolidinone, torezolid phosphate (TR-701), determination of tentative disk diffusion interpretive criteria, and quality control ranges. Antimicrob Agents Chemother. 2010;54(5):2063-2069.

86. Locke JB, Finn J, Hilgers M, et al. Structure-activity relationships of diverse oxazolidinones for linezolid-resistant Staphylococcus aureus strains possessing the cfr methyltransferase gene or ribosomal mutations. Antimicrob Agents Chemother. 2010;54(12): $5337-5343$.

87. Balli EP, Venetis CA, Miyakis S. Systematic review and meta-analysis of linezolid versus daptomycin for treatment of vancomycin-resistant enterococcal bacteremia. Antimicrob Agents Chemother. 2014;58(2): 734-739.

88. Chuang YC, Wang JT, Lin HY, Chang SC. Daptomycin versus linezolid for treatment of vancomycin-resistant enterococcal bacteremia: systematic review and meta-analysis. BMC Infect Dis. 2014; 14(1):687.

89. Reyes K, Zervos M. Endocarditis caused by resistant Enterococcus: an overview. Curr Infect Dis Rep. 2013;15(4):320-328.

90. Pfaller MA, Sader HS, Jones RN. Evaluation of the in vitro activity of daptomycin against 19615 clinical isolates of Gram-positive cocci collected in North American hospitals (2002-2005). Diagn Microbiol Infect Dis. 2007;57(4):459-465.

91. Werth BJ, Steed ME, Ireland CE, et al. Defining daptomycin resistance prevention exposures in vancomycin-resistant Enterococcus faecium and E. faecalis. Antimicrob Agents Chemother. 2014;58(9): 5253-5261.

92. Murray KP, Zhao JJ, Davis SL, et al. Early use of daptomycin versus vancomycin for methicillin-resistant Staphylococcus aureus bacteremia with vancomycin minimum inhibitory concentration $>1 \mathrm{mg} / \mathrm{L}$ : a matched cohort study. Clin Infect Dis. 2013;56(11): 1562-1569.

93. Casapao AM, Kullar R, Davis SL, et al. Multicenter study of highdose daptomycin for treatment of enterococcal infections. Antimicrob Agents Chemother. 2013;57(9):4190-4196.

94. Mueller SW, Kiser TH, Anderson TA, Neumann RT. Intraventricular daptomycin and intravenous linezolid for the treatment of external ventricular-drain-associated ventriculitis due to vancomycin-resistant Enterococcus faecium. Ann Pharmacother. 2012;46(12):e35.

95. Hassoun AA, Coomer RW, Mendez-Vigo L. Intraperitoneal daptomycin used to successfully treat vancomycin-resistant Enterococcus peritonitis. Perit Dial Int. 2009;29(6):671-673.

96. Fisher L, North D. Effectiveness of low-dose daptomycin in the treatment of vancomycin-resistant enterococcal urinary tract infections. Int J Antimicrob Agents. 2009;33(5):493-494.

97. Werth BJ, Barber KE, Tran KN, et al. Ceftobiprole and ampicillin increase daptomycin susceptibility of daptomycin-susceptible and -resistant VRE. J Antimicrob Chemother. 2015;70(2):489-493.

98. Sakoulas G, Rose W, Nonejuie P, et al. Ceftaroline restores daptomycin activity against daptomycin-nonsusceptible vancomycin-resistant Enterococcus faecium. Antimicrob Agents Chemother. 2014;58(3): 1494-1500.

99. Entenza JM, Giddey M, Vouillamoz J, Moreillon P. In vitro prevention of the emergence of daptomycin resistance in Staphylococcus aureus and enterococci following combination with amoxicillin/clavulanic acid or ampicillin. Int J Antimicrob Agents. 2010;35(5): 451-456.

100. Hall Snyder A, Werth BJ, Barber KE, Sakoulas G, Rybak MJ. Evaluation of the novel combination of daptomycin plus ceftriaxone against vancomycin-resistant enterococci in an in vitro pharmacokinetic/pharmacodynamic simulated endocardial vegetation model. J Antimicrob Chemother. 2014;69(8):2148-2154. 
101. Sakoulas G, Bayer AS, Pogliano J, et al. Ampicillin enhances daptomycin- and cationic host defense peptide-mediated killing of ampicillin- and vancomycin-resistant Enterococcus faecium. Antimicrob Agents Chemother. 2012;56(2):838-844.

102. Diaz L, Tran TT, Munita JM, et al. Whole-genome analyses of Enterococcus faecium isolates with diverse daptomycin MICs. Antimicrob Agents Chemother. 2014;58(8):4527-4534.

103. Meagher AK, Ambrose PG, Grasela TH, Ellis-Grosse EJ. The pharmacokinetic and pharmacodynamic profile of tigecycline. Clin Infect Dis. 2005;41(Suppl 5):S333-S340.

104. Curcio D. Treatment of recurrent urosepsis with tigecycline: a pharmacological perspective. J Clin Microbiol. 2008;46(5):1892-1893.

105. Jenkins I. Linezolid- and vancomycin-resistant Enterococcus faecium endocarditis: successful treatment with tigecycline and daptomycin. J Hosp Med. 2007;2(5):343-344.

106. Scheetz MH, Reddy P, Nicolau DP, et al. Peritoneal fluid penetration of tigecycline. Ann Pharmacother. 2006;40(11):2064-2067.

107. Zhanel GG, Calic D, Schweizer F, et al. New lipoglycopeptides: a comparative review of dalbavancin, oritavancin and telavancin. Drugs. 2010;70(7):859-886.

108. Dalvance ${ }^{\circledR}$ (dalbavancin) [package insert]. Chicago, IL: Durata Therapeutics, Inc.; 2014.

109. VIBATIV ${ }^{\circledR}$ (telavancin) [package insert]. Deerfield, IL: Astellas Pharma US; 2009.

110. Baltch AL, Smith RP, Ritz WJ, Bopp LH. Comparison of inhibitory and bactericidal activities and postantibiotic effects of LY333328 and ampicillin used singly and in combination against vancomycinresistant Enterococcus faecium. Antimicrob Agents Chemother. 1998; 42(10):2564-2568.
111. Lefort A, Saleh-Mghir A, Garry L, Carbon C, Fantin B. Activity of LY333328 combined with gentamicin in vitro and in rabbit experimental endocarditis due to vancomycin-susceptible or -resistant Enterococcus faecalis. Antimicrob Agents Chemother. 2000;44(11): 3017-3021.

112. Zhanel GG, Hoban DJ, Karlowsky JA. Nitrofurantoin is active against vancomycin-resistant enterococci. Antimicrob Agents Chemother. 2001;45(1):324-326.

113. Shrestha NK, Chua JD, Tuohy MJ, et al. Antimicrobial susceptibility of vancomycin-resistant Enterococcus faecium: potential utility of fosfomycin. Scand J Infect Dis. 2003;35(1):12-14.

114. Lautenbach E, Schuster MG, Bilker WB, Brennan PJ. The role of chloramphenicol in the treatment of bloodstream infection due to vancomycin-resistant Enterococcus. Clin Infect Dis. 1998;27(5): 1259-1265.

115. Rosenthal VD, Maki DG, Mehta Y, et al; International Nosocomial Infection Control Consortium. International Nosocomial Infection Control Consortium (INICC) report, data summary of 43 countries for 2007-2012. Device-associated module. Am J Infect Control. 2014; 42(9):942-956.

116. Zyvox ${ }^{\circledR}$ (linezolid) [package insert]. New York, NY: Pfizer Inc.; 2007.

117. Cubicin ${ }^{\circledR}$ (daptomycin) [package insert]. Lexington, MA: Cubist Pharmaceuticals; 2010.

118. Tygacil ${ }^{\circledR}$ (tigecycline) [package insert]. Philadelphia, PA: Wyeth Pharmaceuticals; 2011.

119. Sivextro ${ }^{\circledR}$ (tedizolid phosphate) [package insert]. Lexington, MA: Cubist Pharmaceuticals; 2014.

120. Orbactiv $^{\mathbb{B}}$ (oritavancin) [package insert]. Parsippany, NJ: The Medicines Company; 2014.
Infection and Drug Resistance

\section{Publish your work in this journal}

Infection and Drug Resistance is an international, peer-reviewed openaccess journal that focuses on the optimal treatment of infection (bacterial, fungal and viral) and the development and institution of preventive strategies to minimize the development and spread of resistance. The journal is specifically concerned with the epidemiology of antibiotic

\section{Dovepress}

resistance and the mechanisms of resistance development and diffusion in both hospitals and the community. The manuscript management system is completely online and includes a very quick and fair peerreview system, which is all easy to use. Visit http://www.dovepress.com/ testimonials.php to read real quotes from published authors. 